AJChE 2019, Vol. 19, No. 1, 47 - 53

\title{
Plasma-Enhanced Chemical Vapor Deposition of Indene for Gas Separation Membrane
}

\author{
Myat Kyaw *,1,3 \\ Shinsuki Mori ${ }^{2}$ \\ Nathaniel Dugos ${ }^{3}$ \\ Susan Roces ${ }^{3}$ \\ Arnel Beltran ${ }^{3}$ \\ Shunsuke Suzuki ${ }^{2}$ \\ 1 Department of Chemical Engineering, Mandalay Technological University, Mandalay 05072, \\ Myanmar \\ 2 Department of Chemical Engineering, Tokyo Institute of Technology, Tokyo 152-8552, Japan \\ 3 Chemical Engineering Department, De La Salle University, 2401 Taft Ave, Manila 0922, \\ Philippines \\ *e-mail: myatkyaw@mtu.edu.mm
}

Polyindene (PIn) membrane was fabricated onto a zeolite $5 \mathrm{~A}$ substrate by using plasma-enhanced chemical vapor deposition (PECVD) at low temperature. Membrane characterization was done by taking Scanning Electron Microscopy (SEM) and FT-IR measurements and the new peak was found in the plasma-derived PIn film. Membrane performance was analyzed by checking permeability of pure gases $\left(\mathrm{H}_{2}, \mathrm{~N}_{2}\right.$, and $\left.\mathrm{CO}_{2}\right)$ through the membrane. PECVD-derived PIn membrane showed high gas barrier properties and selectivities of 8.2 and 4.0 for $\mathrm{H}_{2} / \mathrm{CO}_{2}$ and $\mathrm{H}_{2} / \mathrm{N}_{2}$, respectively, at room temperature.

Keywords: Indene, Carbon membrane, PECVD, Gas separation

\section{INTRODUCTION}

Membrane technology and gas separation membranes have been applied in hydrogen purification (Tseng et al. 2016), carbon dioxide capture (Haider et al. 2018; Wang et al. 2015), oxygen enrichment (Li \& Huang 1997), and hydrocarbon separation (Semenova 2004) because of its advantages such as low energy requirement and low operating cost (Ismail \& Li, 2008). In this perspective, the interest on inorganic membranes such as carbon membrane for gas separation has also grown for showing higher selectivity and remarkable high thermal and chemical resistances. Generally, a carbon membrane is fabricated by the pyrolysis of an organic precursor and the resultant membrane shows the significant molecular sieving effect in gas separation (Nagasawa et al. 2016). However, the processing temperature of carbonization in the membrane fabrication process via pyrolysis technique is pretty high and it is usually well above $500^{\circ} \mathrm{C}$. Another possible effective method to manufacture a carbon membrane is applying plasma-enhanced 
chemical vapor deposition (PECVD) technique in membrane fabrication. PECVD is a kind of CVD in which plasma is utilized as the energy source and the process can be done at low temperature (Nagasawa et al. 2017). The use of plasma can increase the reactivity of monomers to deposit thin films. As a consequence of this, varieties of material can be utilized as precursors for membrane fabrication (Vasudev et al. 2013). Therefore, interest on utilizing of PECVD in the synthesis of inorganic membrane has been increasing and some research groups already demonstrated fabrication of membrane via PECVD technique (Kafrouni et al. 2009; Nagasawa et al. 2017; Roualdes, Sanchez \& Durand 2002).

The attention on polymeric systems which have aromatic backbones has grown since the product membranes demonstrated an improvement in permeability (Yampolskii 2012). Indene (In) is a polycyclic hydrocarbon which includes a benzene ring. It can be smoothly polymerized to give polymer with the aid of acidic catalyst (Brum, Laux, \& Forte 2013). Goel et al. reported a simple chemical approach to create one dimensional polyindene (PIn) nanofiber by the use of a single step cationic polymerization reaction (Goel, Mazumdar \& Gupta 2010). Moreover, In can also be polymerized in a living fashion to prepare random copolymers with high molecular weight. In became an attractive and significant polymeric material in the previous couple of years because of its cyclic structure and for showing a planar conformation and high glass transition temperature after polymerization (Abdul
Karim, Nomura \& Masuda 2002). Nevertheless, regardless of its proven exceptional characteristics, the synthesis of In as a gas barrier film is still an unexplored area and no attempt has yet been made to fabricate PIn as a gas barrier film. Fabrication of PIn film as a gas barrier layer using PECVD method and studying its gas separation properties will fulfil the desire to generate new candidates for gas separation membrane.

Herein, we report successful fabrication of polyindene (PIn) membrane on zeolite 5A substrate prepared via PECVD at low temperature. Moreover, characterization of deposited film and permeabilities of gases through PIn film and their selectivities are also presented.

\section{MATERIAL AND METHOD Material}

In this work, Zeolite 5A was obtained from GL Science Japan and was used as substrate material without any treatment. $1^{\text {st }}$ Grade Indene (In) was purchased from Wako Chemical Company and utilized as precursor for carbon source. For generating plasma source, Dressler Cesar ${ }^{\circledR}$ RF Power Generator was used.

\section{Experimental Procedure}

Firstly, the substrate was fabricated on glass tube and set up in PECVD system. As shown in Fig. 1, PECVD was organized in a reactor supplied with an $\mathrm{RF}$ coil run at $13.56 \mathrm{MHz}$ and power was stable at $20 \mathrm{~W}$. Indene (In) was transported to the reactor at the flow rate of $0.2 \mathrm{sccm}$. The flow rate of In was controlled by the flow rate of $\mathrm{Ar}$ carrier gas (2 sccm). The pressure and temperature of the bubbler were at $1 \mathrm{kPa}$ 


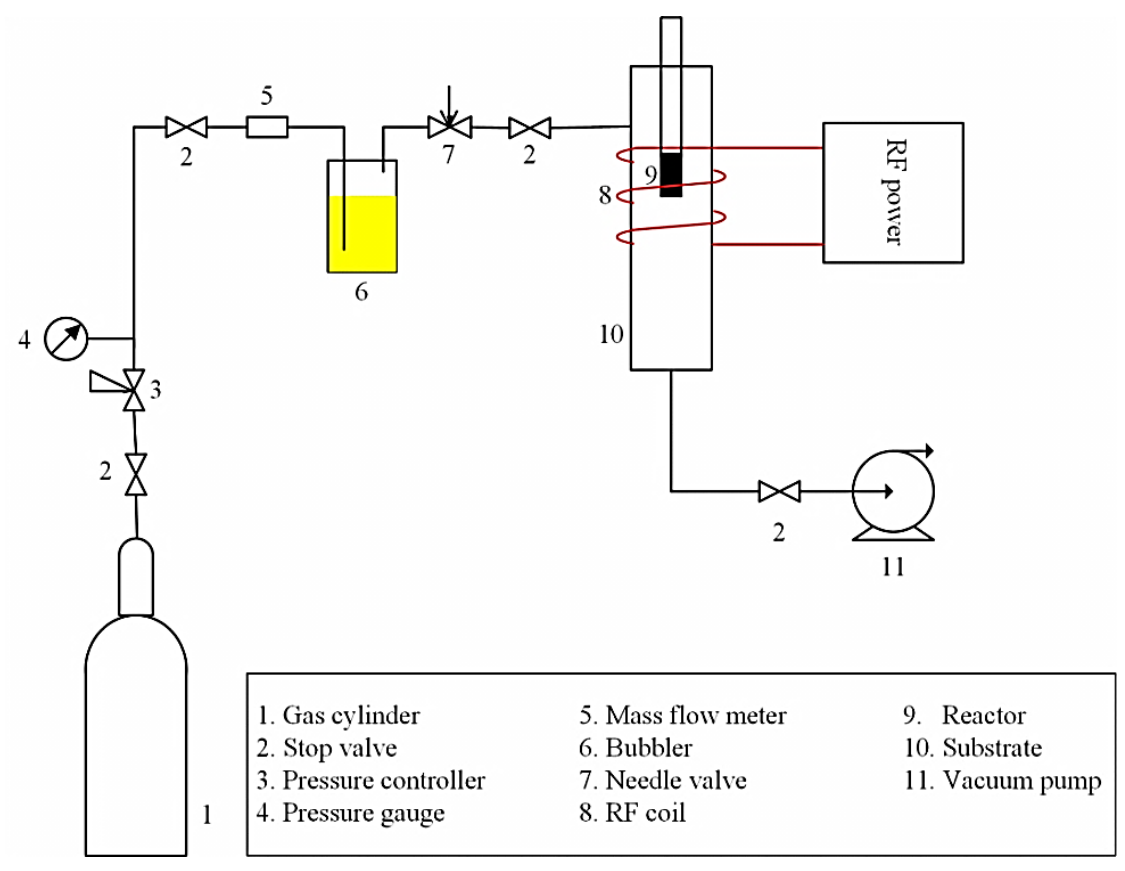

Fig. 1: Schematic diagram of the PECVD equipment

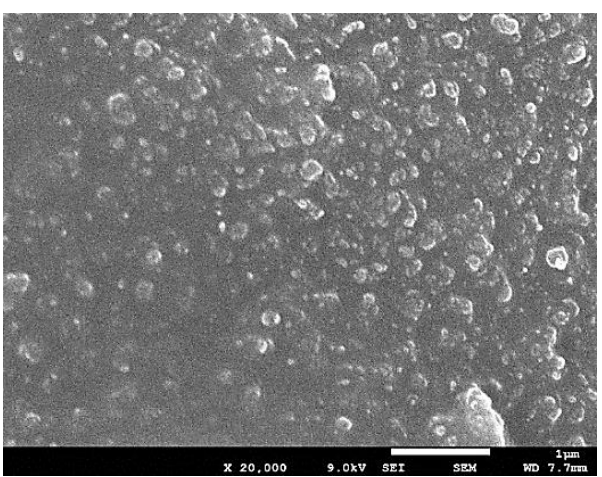

(a)

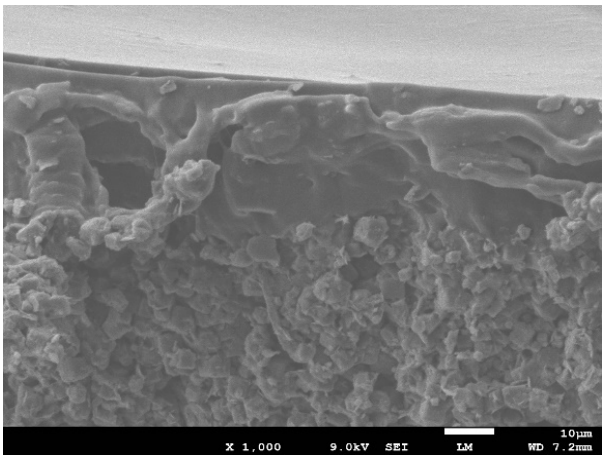

(b)

Fig. 2: SEM image of (a) the surface view (scale bar is $1 \mu \mathrm{m}$ ) and (b) the cross-sectional view (scale bar is $10 \mu \mathrm{m})$ of an indene deposited film and $20^{\circ} \mathrm{C}$, respectively. The pressure in the reactor was maintained at around $30 \mathrm{~Pa}$ throughout the deposition process. Pure gas permeation through the PIn membrane was done at room temperature by using custom gas filtration equipment.

\section{RESULTS AND DISCUSSION}

Fig. 2 shows the scanning electron microscopy (SEM) images of surface and side view of PIn layer growth after $1.5 \mathrm{hr}$ deposition. Scanning electron microscope (SEM) revealed that the plasma-derived PIn layer was continuous and showed a liquid film structure. The PIn layer coated the whole surface of substrate layer with no obvious cracks. The thickness of the PIn layer was about $20 \mu \mathrm{m}$ after $1.5 \mathrm{hr}$ of deposition. 


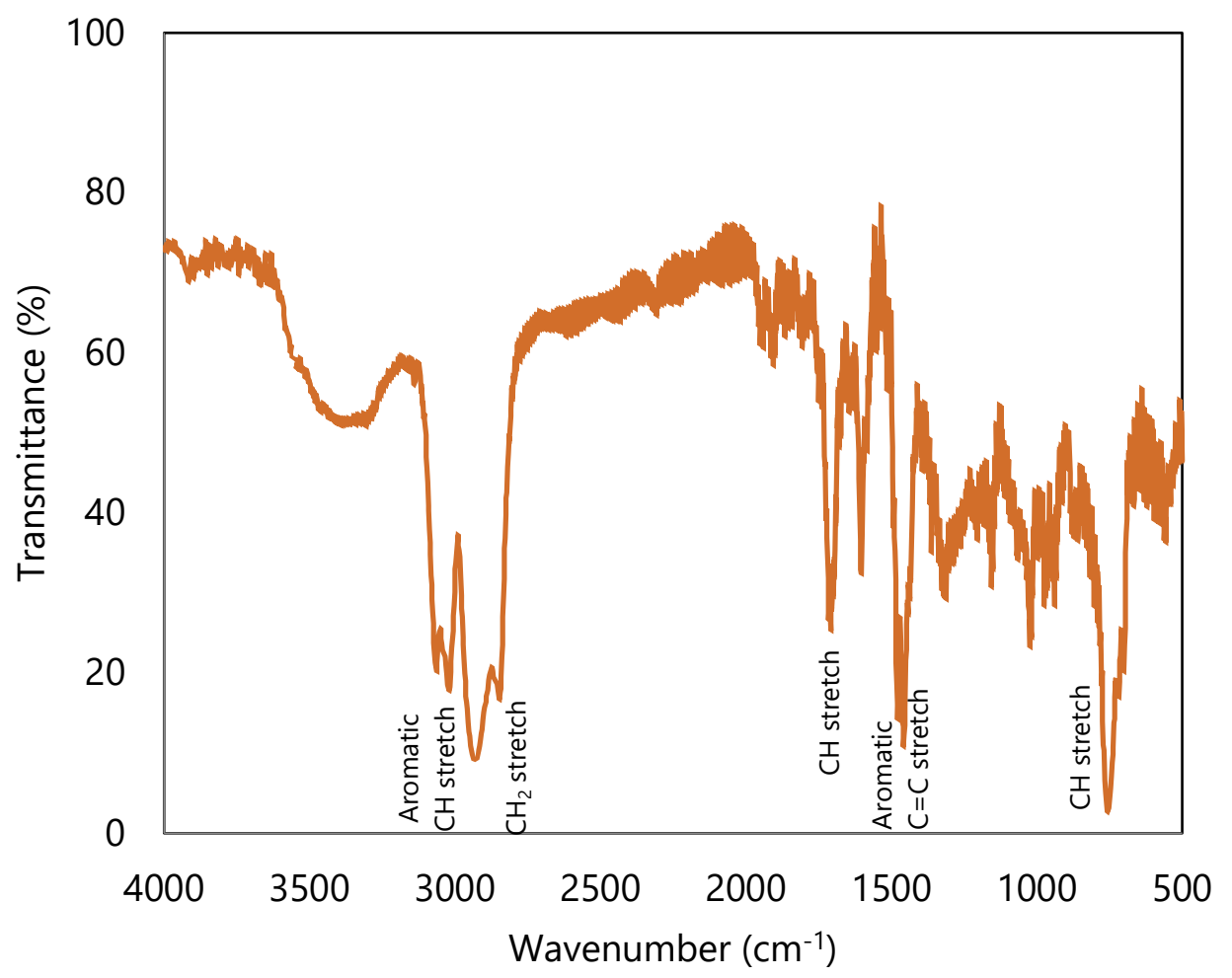

Fig. 3: FT-IR of PECVD-deposited PIn film

Fig. 3 shows FTIR spectra characterized for the PECVD-derived PIn film. The FT-IR spectra of PIn film shows broad peaks and $\mathrm{C}-\mathrm{H}$ stretch are prominent. The additional peak was observed at $1708 \mathrm{~cm}^{-1}$ and it showed polyindene has conjugated aldehydes and ketones $(C=O)$. Normally, band for aldehydes and ketones can be observed at $1720 \mathrm{~cm}^{-1}$. However, because of the presence of a conjugated $\pi$ bond or an aromatic ring, the band's frequency may be lower by $20-30 \mathrm{~cm}^{-1}$. In this case, PIn layer contains aromatic rings according to the band at $3016 \mathrm{~cm}^{-1}$. Therefore, band for $\mathrm{C}=\mathrm{O}$ stretch was observed at the lower frequency of 1708 $\mathrm{cm}^{-1}$. The main $\mathrm{CH}$ stretching band of the aromatic ring lies at $3024 \mathrm{~cm}^{-1}$. The band at $3028 \mathrm{~cm}^{-1}$ is combinations of the $\mathrm{CH}$ frequencies in the range of $1600-1800 \mathrm{~cm}^{-}$
1. The strong 2845 and $2939 \mathrm{~cm}^{-1}$ bands are the characteristic stretching frequencies of the $\mathrm{CH}_{2}$ group. The larger frequency represents the unsymmetrical mode, and the lower frequency represents the symmetrical one. The $1456 \mathrm{~cm}^{-1}$ bending mode for aromatic $\mathrm{C}=\mathrm{C}$ stretch is also strong. The $\mathrm{C}=\mathrm{C}$ stretching vibration of aromatic ring is represented by a band at $1458 \mathrm{~cm}^{-1}$. Based on FT-IR results, there are sufficient polar sites in the plasmaderived PIn film for preferential interaction and sorption of polar $\mathrm{CO}_{2}$ gas. There is also the strong $\mathrm{CH}$ stretch, aromatic outof-plane bend, lies at $754 \mathrm{~cm}^{-1}$ in fingerprint region.

Fig. 4 shows the pure gas permeance of $\mathrm{H}_{2}, \mathrm{CO}_{2}$ and $\mathrm{N}_{2}$ through PIn membrane as a function of deposition time at room temperature. Herein, the permeances of 
deposition time " 0 " shows the permeances of pure gases through the substrate before the plasma-deposition.

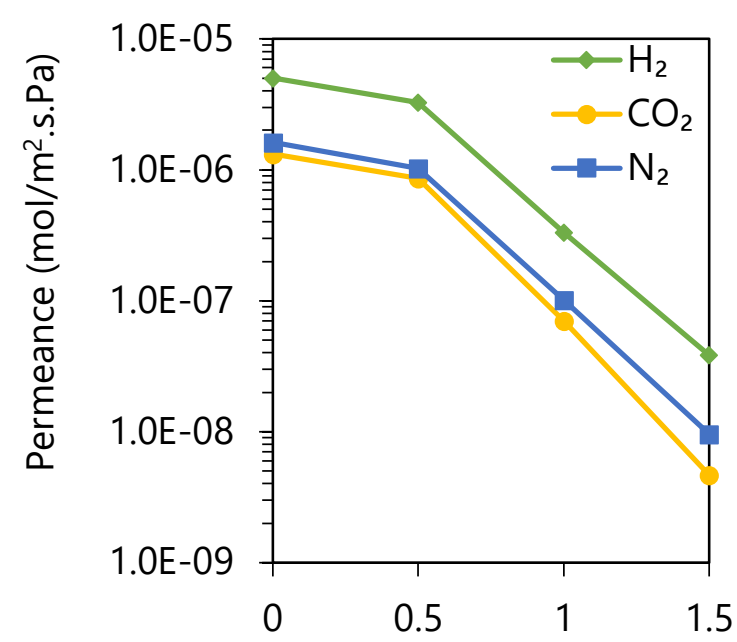

Fig. 4: Pure gas permeance of $\mathrm{H}_{2}, \mathrm{CO}_{2}$ and $\mathrm{N}_{2}$ through PIn membrane as a function of deposition time at room temperature

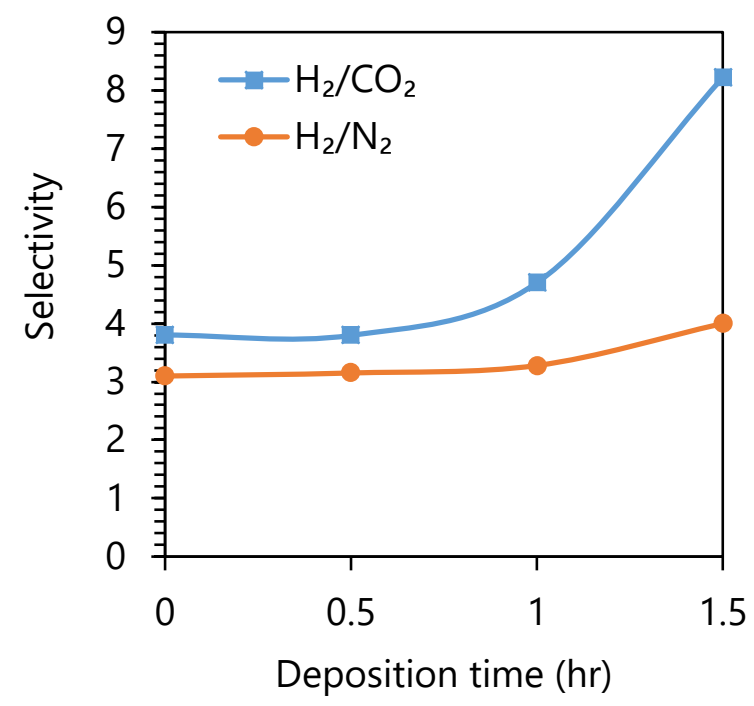

Fig. 5: Separation factor of $\mathrm{H}_{2} / \mathrm{CO}_{2}$ and $\mathrm{H}_{2} / \mathrm{N}_{2}$ through PIn membrane as a function of deposition time at room temperature

Fig. 5 shows separation factor for $\mathrm{H}_{2} / \mathrm{CO}_{2}$ and $\mathrm{H}_{2} / \mathrm{N}_{2}$ systemes evaluated by the the permeance ratios of $\mathrm{H}_{2} / \mathrm{CO}_{2}$ and
$\mathrm{H}_{2} / \mathrm{N}_{2}$, respectively. The PIn membrane exhibited higher selectivity and lower permeance increasing deposition time. After $0.5 \mathrm{hr}$ (30 $\mathrm{min}$ ) of deposition, the PIn membrane displayed a $\mathrm{H}_{2}$ permeance of $3.25 \times 10^{-6} \mathrm{~mol} / \mathrm{m}^{2}$.s.Pa. The permeance of $\mathrm{H}_{2}$ sharply declined in the succeeding deposition increasing the permeance ratio. For example, the permeance of $\mathrm{H}_{2}$ decreased from $5.02 \times 10^{-6} \mathrm{~mol} / \mathrm{m}^{2}$.s.Pa of the original substrate to $3.83 \times 10^{-8}$ $\mathrm{mol} / \mathrm{m}^{2}$.s.Pa after $1.5 \mathrm{hr}$ deposition. Moreover, separation factor for $\mathrm{H}_{2} / \mathrm{CO}_{2}$ and $\mathrm{H}_{2} / \mathrm{N}_{2}$ also increased to 8.2 and 4.0, respectively, after $1.5 \mathrm{hr}$ deposition.

\section{CONCLUSION}

Polyindene (PIn) membrane was fabricated onto a Zeolite $5 \mathrm{~A}$ substrate via radio frequency plasma-enhanced chemical vapor deposition (PECVD) technique at low temperature. The plasma-derived Polyindene (PIn) film was continuous and there was no significant defect on the layer. The additional peak was observed in the PIn film and it is the feature of plasma-derived polymer film. The resultant membrane showed very low permeance of gases and high selectivity for $\mathrm{H}_{2} / \mathrm{CO}_{2}$ and $\mathrm{H}_{2} / \mathrm{N}_{2}$ system at room temperature. This study revealed that Indene (In) can be utilized as a new polymeric precursor to the fabrication of a carbon membrane for low pressure PECVD system at low temperature.

\section{ACKNOWLEDGEMENT}

The authors would like to thank the Japan International Cooperation Agency 
(JICA) for the financial support through the ASEAN University Network/Southeast Asia Engineering Education Development Network (AUN/SEED-Net).

\section{REFERENCES}

1. Abdul Karim, S. M., Nomura, R., and Masuda, T. (2002). "Cationic copolymerization of indene with styrene derivatives: Synthesis of random copolymers of indene with high molecular weight," Journal of Polymer Science, Part A: Polymer Chemistry, 40(14), 2449-2457.

2. Brum, F. J. B., Laux, F. N., and Forte, M. M. C. (2013). "Synthesis of hydrocarbon polymers by cationic polymerization and their thermal properties. Designed Monomers and Polymers," 16(3), 291-301.

3. Goel, S., Mazumdar, N. A., and Gupta, A. (2010). "One-dimensional nanofibers of polyindene: Synthesis and characterization," Journal of Polymer Research, 17(5), 639-645.

4. Haider, S., Lindbråthen, A., Lie, J. A., Andersen, I. C. T., and Hägg, M. B. (2018). "CO2 separation with carbon membranes in high pressure and elevated temperature applications," Separation and Purification Technology, 190, 177-189.

5. Ismail, A. F., and Li, K. (2008). "From Polymeric Precursors to Hollow Fiber Carbon and Ceramic Membranes," Membrane Science and Technology, 13(07), 81-119.

6. Kafrouni, W., Rouessac, V., Julbe, A., and Durand, J. (2009). "Synthesis of PECVD a-SiCXNY:H membranes as molecular sieves for small gas separation," Journal of Membrane Science, 329(1-2), 130-137.

7. Li, X., and Huang, M. (1997). "Multilayer ultrathin-film composite membranes for oxygen enrichment," Journal of Applied Polymer Science, 66(11), 2139-2147.

8. Nagasawa, H., Kanezashi, M., Yoshioka, T., and Tsuru, T. (2016). "Plasma-enhanced chemical vapor deposition of amorphous carbon molecular sieve membranes for gas separation," RSC Advances, 6(64), 59045-59049.

9. Nagasawa, H., Yamamoto, Y., Tsuda, N., Kanezashi, M., Yoshioka, T., and Tsuru, T. (2017). "Atmosphericpressure plasma-enhanced chemical vapor deposition of microporous silica membranes for gas separation," Journal of Membrane Science, 524, 644-651.

10. Roualdes, S., Sanchez, J., and Durand, J. (2002). "Gas diffusion and sorption properties of polysiloxane membranes prepared by PECVD," Journal of Membrane Science, 198(2), 299-310.

11. Semenova, S. I. (2004). "Polymer membranes for hydrocarbon separation and removal," Journal of Membrane Science, 231(1-2), 189207.

12. Tseng, H. H., Wang, C. T., Zhuang, G. L., Uchytil, P., Reznickova, J., and Setnickova, K. (2016). "Enhanced $\mathrm{H}_{2} / \mathrm{CH}_{4}$ and $\mathrm{H}_{2} / \mathrm{CO}_{2}$ separation by carbon molecular sieve membrane coated on titania modified alumina support: Effects of $\mathrm{TiO}_{2}$ intermediate 
layer preparation variables on interfacial adhesion," Journal of Membrane Science, 510, 391-404.

13. Vasudev, M. C., Anderson, K. D., Bunning, T. J., Tsukruk, V. V., and Naik, R. R. (2013). "Exploration of plasmaenhanced chemical vapor deposition as a method for thin-film fabrication with biological applications," ACS Applied Materials and Interfaces, 5(10), 3983-3994.
14. Wang, Z., Li, P., Zhihua, Q., Liu, Y., Cao, X., Li, W., and Wang, S. (2015). "Recent developments in membranes for efficient hydrogen purification," Journal of Membrane Science, 495, 130-168.

15. Yampolskii, Y. (2012). "Polymeric Gas Separation Membranes," Macromolecules, 45(8), 3298-33. 



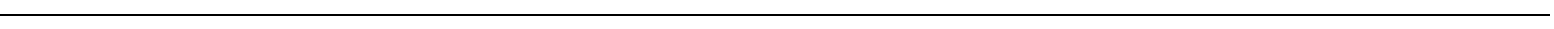

